شناسايى هاى بيوسته به برخى صفات دانه در كندم نان با استفاده از نقشهيابى ارتباطى

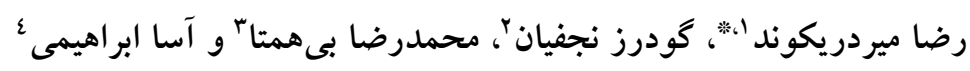

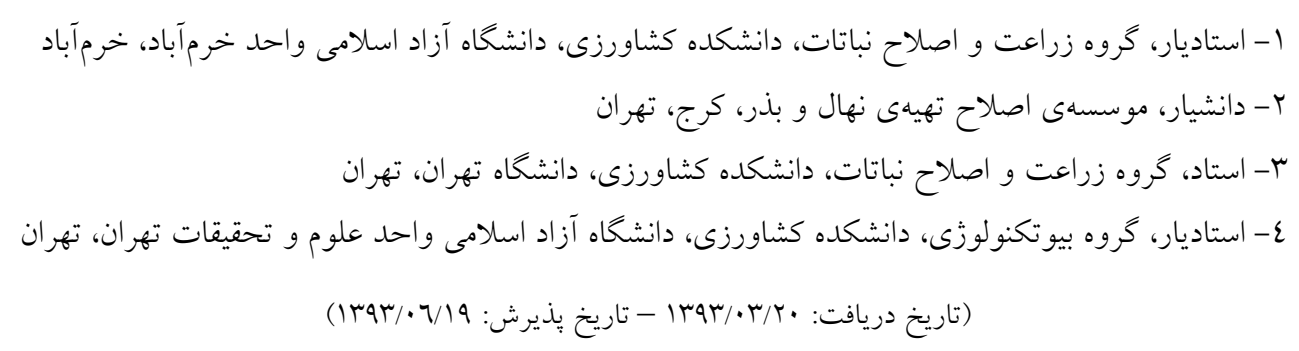

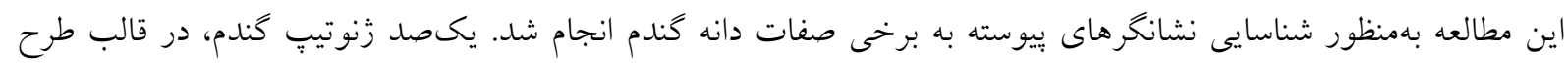

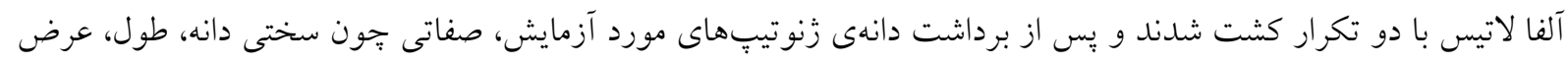

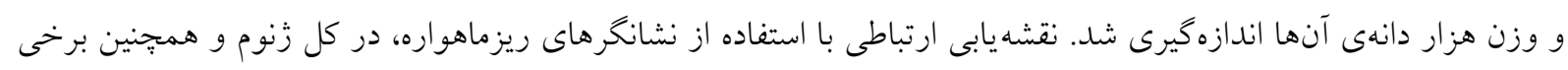

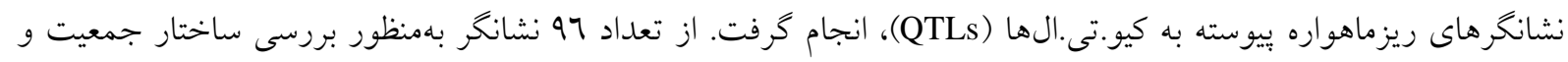

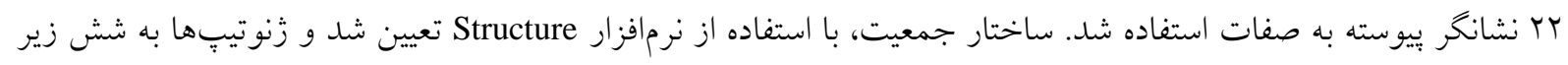

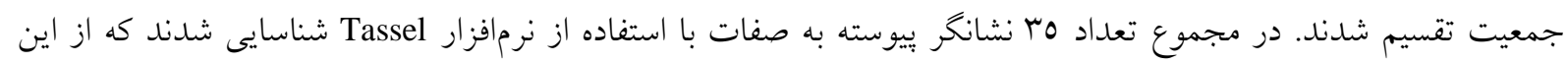

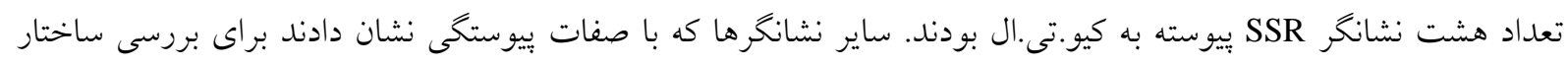

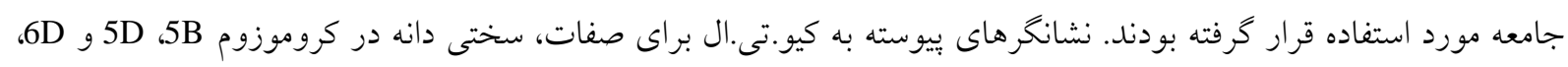

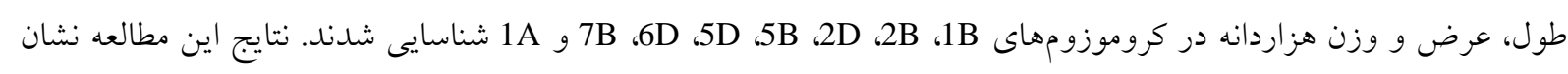

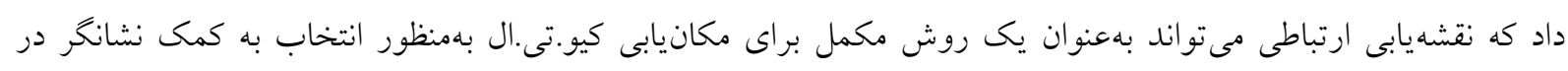
كُندم نان مورد استفاده قرار كيرد.

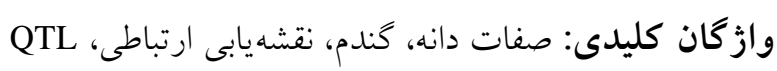


كندمهاى با اندازهى دانه بزرگتر نسبت به گندمهاى دانه

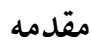

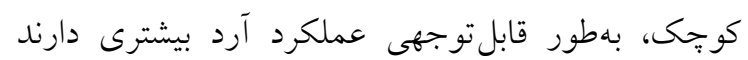
Wiersma (Marshall et al., 1986) (et al., 2001

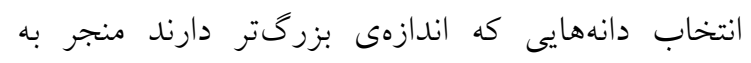

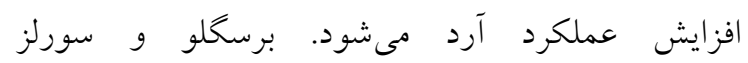
(Breseghello and Sorrells, 2006)، بين طول، وزن، برسن، سطح بذر و كيفيت آسياب شدن دانه كندم رابطهى مثبت بين

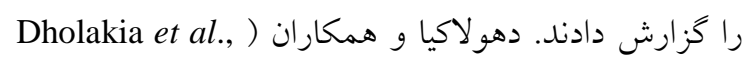
2001) و برسخلو و سورلز ( Breseghello and Sorrells, 2007)، همبستكى مثبت و معنى دار بين صفات وزن دون دانه،

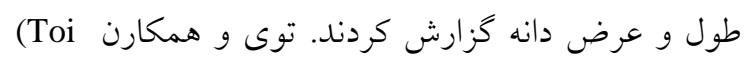
ot al., 2010) Ramya et al., ( صفات گزارش كردند. راميا و همكاران

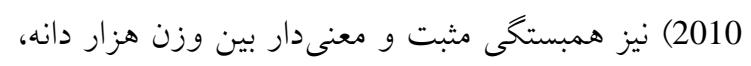
طول و عرض دانه را گزارش كردند.

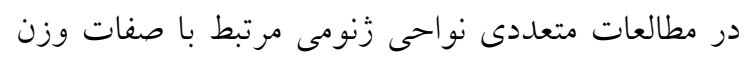

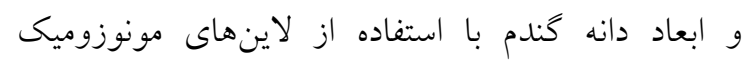
(Giura and Saulescu, 1996; Varshney et al., 2000) و تجزيه كيو.تى.ال ) Ammiraju et al., 2001 and 2004; Dholakia et al., 2003; Kumar et al., 2006; Breseghello and Sorrells, 2006 and 2007 شدهاند. شناخت اساس زنتيكى خصوصيات دانهى گُندم

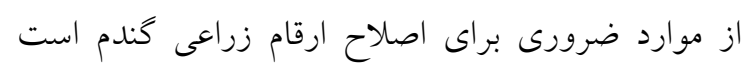

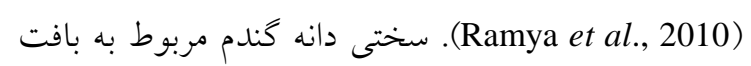

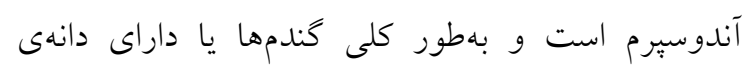
سخت و يا داراى دانه نرم هستند. اين صفت در آسياب

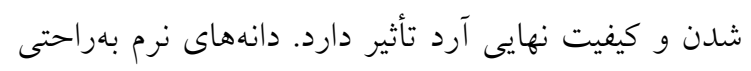

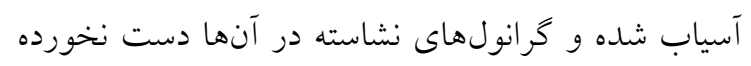
باقى مىمانند و نشاسته در آنها خسارت كمترى مى بيند

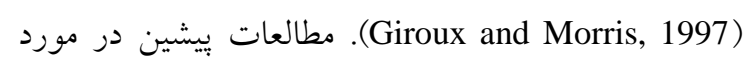
وراثت صفت سختى دانه كندم نشان داده است كه اين صفت تحت كتترل يك زن اصلى و زنهاى فرعى داته

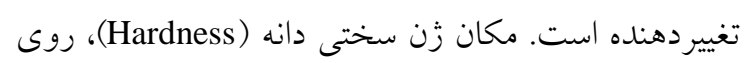


كرفت (جدول (). از صد زنوتيب 1 نمونه كندم دوروم و

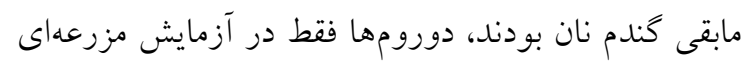

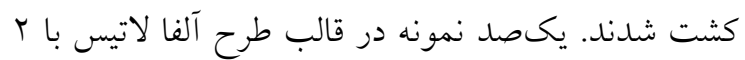
تكرار در مزرعه تحقيقاتى موسسهى تحقيقات اصلاح و

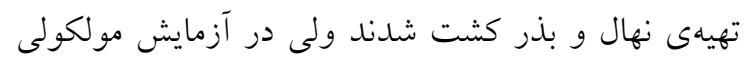

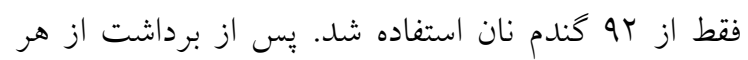
رقم نمونه بذرى تهيه شد و صفات سختى دانه، طول،

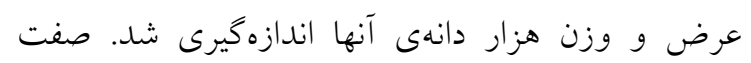

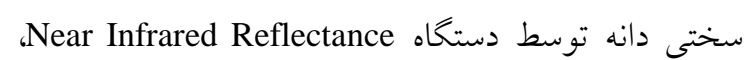
طبق بروتكل استاندارد شيميدانان غلات American Association of Cereal Chemists)

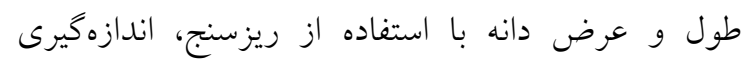
شدند. استخراج DNA با استفاده از روش CTAB، انجام شد (Doyle and Doyle 1987). بهمنظور حذف RNA از ماز

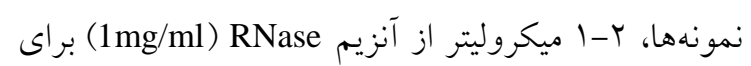

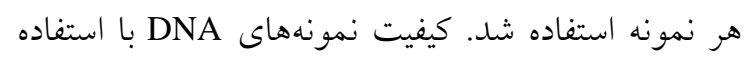

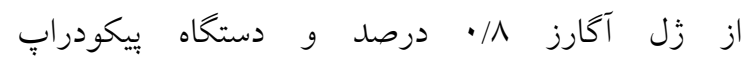
مدلPico200 (ساخت كميانى Picodrop انخحلستان)، تعيين گرديد. سبس از هـNA نمونهايى با غلظت 0.ng تهيه شد. 0.ng

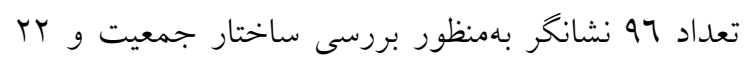

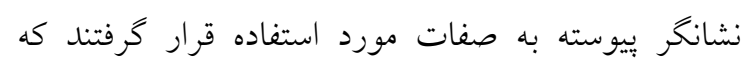

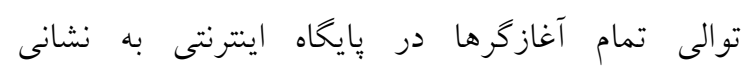
http://wheat.pw.usda.gov/GG2 براى انجام واكنشهاى PCR از روش رودر و همكاران و به اين صورت استفاده شد كه ونه (Roder et al., 1998) يكى جرخه در دماى عq درجه و به مدت ع دقيقه،

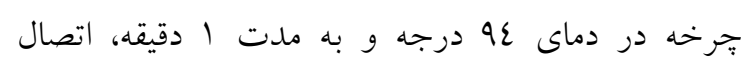

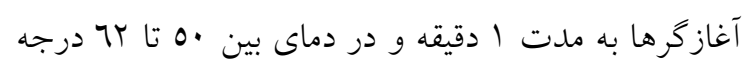

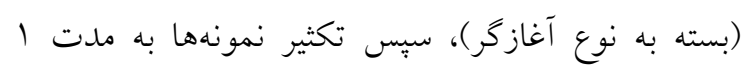

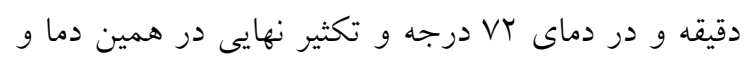

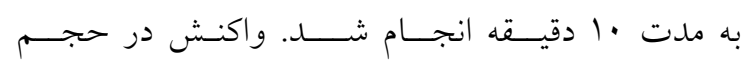

Mattern et al., ) بازوى كوتاه كروموزوم 1973 مرار دارد 1973). مطالعات متعددى با استفاده از تجزيه كيو.تى.ال براى شناسايى مكانهاى كنترل كننده اين صفت انجام

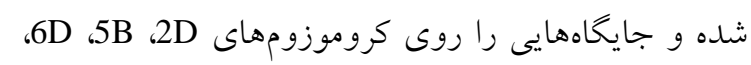
Sourdill et al.,1996; ) 2A و شناسايى نمودهاند Campbell et al., 1999; Perretant et al., 2000; Galande et al., 2001; Igrejas et al., 2002; Narasimhamoorthy et al., 2006 لاينهاى نوتركيب كندم نان در جّند محيط انجام شد،

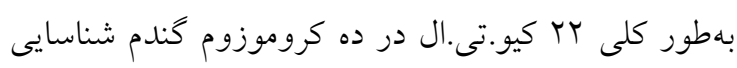

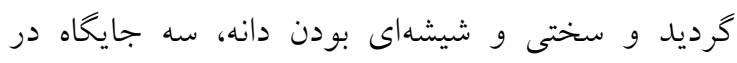

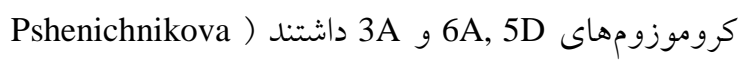
Breseghello and (et al., 2008 (et). برسخلو و سورون Sorrells, 2006 ، با استفاده از نقشهيابى ارتباطى در ارقام كندم نان مشخص كردند كه كروموزوم 2D در كنترل

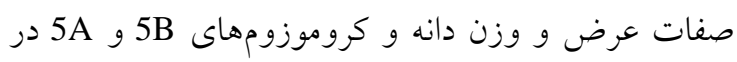

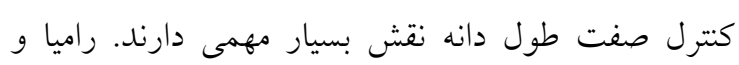

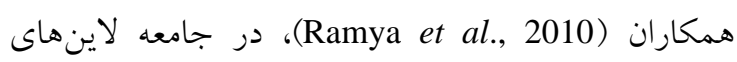
نوتركيب كندم نان با استفاده از نقشهيابى كيو.تى.ال، · 1.

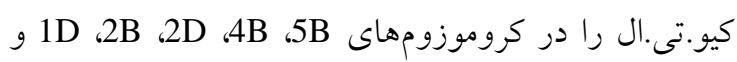
5D براى وزن هزار دانه شناسايى كردند، درحالى كه براى دروز

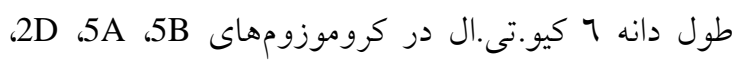

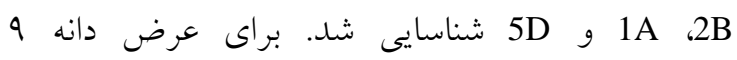

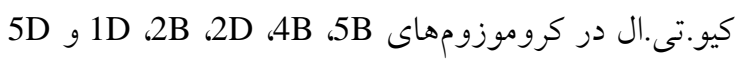
وجود داشت. هدف از انجام اين تحقيق بررسى ارتباط مكانهاى كمى دانى

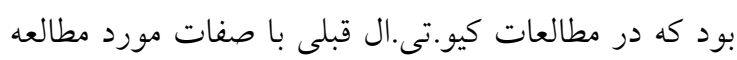

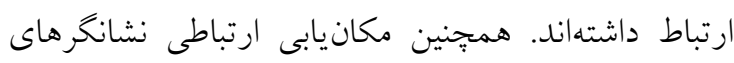

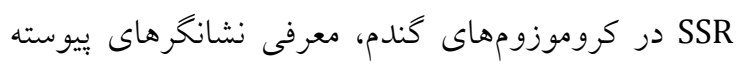

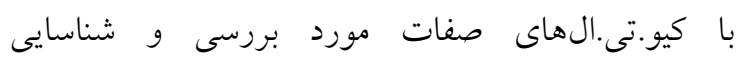
كيو.تى.الهاى جند اثره (Pleiotropic)، بود.

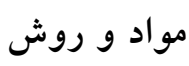

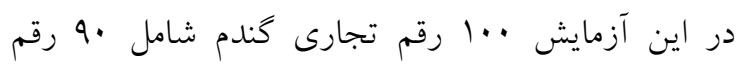
زراعى و •ا لاين اميدبخش كه از موسسهى تحقيقات اصلاح و تهيهى نهال و بذر، تهيه شدند، مورد استفاده قرار 
جدول ا- اسامى يا شناسه زنوتيبهاى گندم مورد استفاده در تحقيق

Table 1. Names or identity of wheat genotypes used in the study

\begin{tabular}{|c|c|c|c|c|c|c|c|c|c|c|c|}
\hline رديف & نام/شناسه & رديف & نام/شناسه & رديف & نام/شناسه & رديف & نام/شناسه & رديف & نام/شناسه & رديف & نام/شناسه \\
\hline No. & Name/ Identity & No. & Name/ Identity & No. & Name/ Identity & No & Name/ Identity & No. & Name/ Identity & No. & Name/ Identity \\
\hline 1 & Karaj-1 & 18 & $\mathrm{DN}-11$ & 35 & Khazar-1 & 52 & Falat & 69 & Adl & 86 & Aria \\
\hline 2 & Karaj-2 & 19 & Bezostaya & 36 & Mughan-1 & 53 & Heirmand & 70 & Sardari & 87 & Dena \\
\hline 3 & Karaj-3 & 20 & Navid & 37 & Mughan-2 & 54 & Darab-2 & 71 & Azar-2 & 88 & Behrang \\
\hline 4 & Azadi & 21 & Alamout & 38 & Mughan-3 & 55 & Atrak & 72 & Zagross & 89 & UN-11 \\
\hline 5 & Ghods & 22 & Alvand & 39 & Golestan & 56 & Chamran & 73 & Sabalan & 90 & Kohdasht \\
\hline 6 & Mahdavi & 23 & Zarin & 40 & Alborz & 57 & Star & 74 & Sp.Bc of Roshan & 91 & Ohadi \\
\hline 7 & Niknejad & 24 & MV-17 & 41 & Kaveh & 58 & Dez & 75 & Wi. Bc of Roshan & 92 & Dehdasht \\
\hline 8 & Marvdasht & 25 & Gaspard & 42 & Rassoul & 59 & Vee/Nac & 76 & Cross of Shahi & 93 & Pato \\
\hline 9 & Pishtaz & 26 & Gascogne & 43 & Tajan & 60 & Line A & 77 & Maroon & 94 & Rasad \\
\hline 10 & Shiraz & 27 & Soisson & 44 & Shiroudi & 61 & Aflak & 78 & Kavir & 95 & Hama-4 \\
\hline 11 & Sepahan & 28 & Shahriar & 45 & Darya & 62 & Baaz & 79 & Hamoon & 96 & $\mathrm{Ch}$ \\
\hline 12 & Bahar & 29 & Tous & 46 & Arta & 63 & Shahpasand & 80 & Bam & 97 & Homa \\
\hline 13 & Parsi & 30 & Pishgam & 47 & Morvarid & 64 & Omid & 81 & Akbari & 98 & Seimareh \\
\hline 14 & Sivand & 31 & C-84-8 & 48 & $\mathrm{~N}-85-5$ & 65 & Roshan & 82 & Sistan & 99 & Saji \\
\hline 15 & M-85-7 & 32 & Oroom & 49 & Arvand & 66 & Tabassi & 83 & Arg & 100 & Norstar \\
\hline 16 & WS-82-9 & 33 & Zaree & 50 & Chenab & 67 & Sholleh & 84 & Yavarous & & \\
\hline 17 & WS- $85-10$ & 34 & Inia & 51 & Bayat & 68 & Sorkhtokhm & 85 & Karkheh & & \\
\hline
\end{tabular}

No. of $84,85,86,87,88,92,98$ and 99 are durum wheat and the others are bread wheat.

ييشنهاد كردهاند از نرمافزار Structure با ...... بار اجرا در زمان (Burn in time) و و (...... يا تعداد زير جمعيت از ال استفاده شد. (Permutation) تا 10 تنظيم و 0 دور تكرار (Iteration) در هر زيرگروه انتخاب شد. سبس ماتريس دادههاى مولكولى و ماتريس صفات مورد بررسى و ماتريس كيو (ماتريس ساختار جمعيت) به نرمافزار Tassel نسخه ب// متنقل شدند (قابل دسترس در www.maizegenetics.net). تحليل ارتباط بين صفت و نشانكر با استفاده از مدل ركرسيون خطى درسي مركب با استفاده از نرم|فزار فوق انجام شد. نتايج و بحث

تعداد زير جمعيت مناسب، زير جمعيتىهايى هستند كه

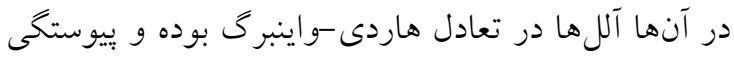

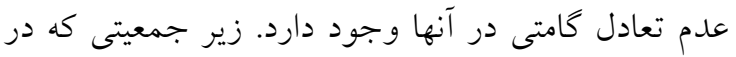

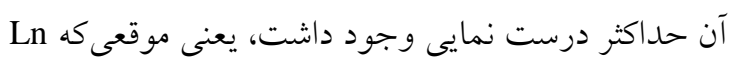
Prob of Data

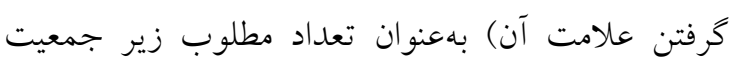

هy cycler اميكروليتر با استفاده از دستخاه ترموسايكلر ساخت كميانى Bio Rad انجام شد. پِس از انجام مراحل تكثير توسط PCR، به هر نمونه r مايكروليتر از محلول

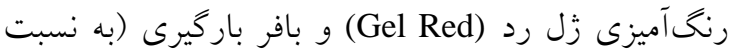

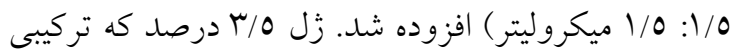

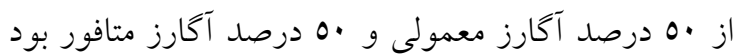
كه با استفاده از بافر TBE تهيه شد. الكتروفورز با ولتاز

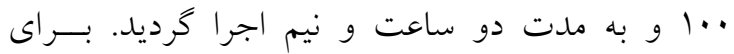

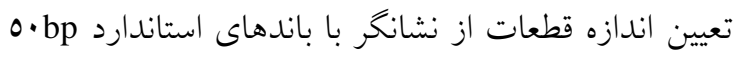
استفاده كرديد. مشاهده و عكسبردارى زير نور به كمك لنك دستخاه Gel Doc XR (ساخت كمبانى Bio Rad آمريكا)

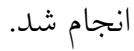
ساختار جمعيت و تهيه ماتريس كيو (Q matrix) با سا

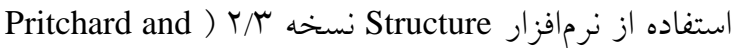
Wen, 2010 ، تعيين شد. براى تعيين تعداد زيركروهها در مر جمعيت از دادهاى زنوتيبى نشانكر SSR استفاده شد. بر

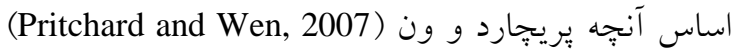


قرار داشت (Crepieux et al., 2005). همجنين در مطالعهى ديخرى دو نشانخر مرتبط با سختى دانه شناسايى شد كه يكى از آنها خيلى نزديك به زن PinbD1 و مكان زنى Ha بود و ديخرى در بازوى كوتاه كروموزوم واقع شده بود. (جايىكه زن Glu-A3 قرار داشت) (Arbelbide and Bernardo, 2006) مختلف كزارش شده كه مكان زنى Ha كه در بازوى كوتاه كروموزوم 5D قرار دارد، در كنترل صفت فوق نتش دارد و در اين مطالعه نيز نشانخر Xcfd18 ارتباط معنىدار با اين صفت داشت، بنابراين اين نشانكر بهعنوان يكى از نشانخرهاى بيوسته به كيو.تى.ال و مؤثر در كنترل صفت سختى دانه معرفى مىشود. علاوه بر اين نشانخر، در 5B مطالعهى حاضر نشانخرهايى كه روى كروموزومهاى و قرار دارند، بهدليل آنكه در جند مورد با اين صفت بيوستخى نشان دادند، بنابراين در كنترل اين صفت نقش Ramya et al., ) دارند. در بررسى هاى راميا و همكاران

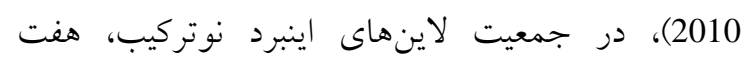

نشانگر Xbarc13، Xbarc146، Xbnarc148، Xbarc178 Xcfd59 Xcfd5 و Xgwm539 كه با صفت وزن هزار دانه بيوسته بودند، مورد استفاده قرار گرفتند. در مطالعهى حاضر همبستخى ارتباطى مشخص كرد كه تنها سه نشانگر Xbarc13 Xcfd5 كروموزومهاى 6D، 5B، 2B و 2D قرار دارند، با صفت فوق ييوستخى معنىدار دارند. علاوه بر اين، نشانخرهاى: Xcfa2164 كروموزومهاى 3A و 7B قرار دارند، نشانخرهاى Xcfa2153 كه روى كروموزوم Xbarc80 كه روى كروموزوم 1A قرار دارد، Xcfd56 بيوسته با صفت عرض دانه كه روى كروموزومهاى 5B-6D قرار دارد با اين صفت بيوستخى معنى دار نشان دادند. همجنين نشانخرهاى Xgwm99، Xgwm149 و Xgwm274 كه براى بررسى ساختار جامعه استفاده شدند و به ترتيب روى كروموزومهاى 1A، 4B و 7B، 3B، 3B، قرار
انتخاب شد. بدين منظور نمودار Ln Prob of Data ترسيم و نقطهاى كه در آن نمودار نزولى شد تعيين گرديد و ديده شد كه حداكثر درست نمايى در K=7 بهدست مى آيد و بنابراين بهعنوان تعداد مناسب K يا تعداد زير جمعيت در نظر گرفته شد. بر اين اساس زنوتيِّها در 7 زير جمعيت قرار گرفتند. حاصل تجزيه ساختار جمعيت Population) structure) را در زيركروهها مشخص نمود. بنابراين براى تجزيه و تحليلهاى بعلى از اين ماتريس كه شش ستون و رديف داشت، استفاده شد. براى بررسى ارتباط نشانخر و صفت علاوه بر ماتريس كيو، دو ماتريس صفت و دادههاى حاصل از امتيازدهى به نوارهاى حاصل از نشانخر SSR نيز مورد استفاده قرار كرفت. دادههاى حاصل از اين سه ماتريس وارد نرمافزار تاسل شده و با استفاده از مدل رگرسيون خطى مركب Mixed) ارتباط بين صفات و دادههاى نشانخرى liner model) بررسى شد. نتايج ارتباط صفات با نشانكرها براى صفات در جدول r آورده شده است. از جِهار نشانگر كه بر Kunert et al., ) اساس مطالعات قبلى كانرت و همكاران 2007)، لى و همكاران (Lie et al., 2008) و زانخ و همكاران (Zhang et al., 2011)، مرتبط با صفت سختى دانه معرفى شده بودند، استفاده شد. در مطالعهى حاضر از اين نشانكرها، تنها نشانگر Xcfd18 كه روى كروموزوم 5D قرار دارد با اين صفت بيوستخى معنى دار نشان داد.

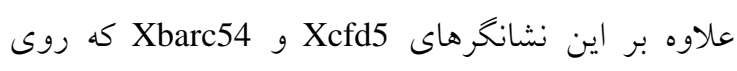
كروموزومهاى 5B-6D و 3A-6D، نشانخر روى كروموزوم 2A، نشانخر Xgwm259 روى كروموزوم

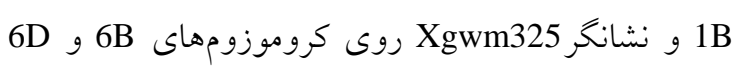
قرار دارند با اين صفت بيوستخى معنىدار داشتند. در مطالعهاى كه با استفاده از تجزيهى كيو.تى.ال در كندم انجام شد، دو كيو.تى.ال براى سختى دانه شناسايى شد كه يكى از آنها در بازوى كوتاه كروموزوم 5D قرار داشت و ديخرى در كروموزوم 1D و نزديك مكان زنى Glu-D1 


$$
\text { جدول Y- تجزيهى همبستخى ارتباطى نشانخر هاى بيوسته و صفات }
$$

Table 2. Association of SSR markers with traits

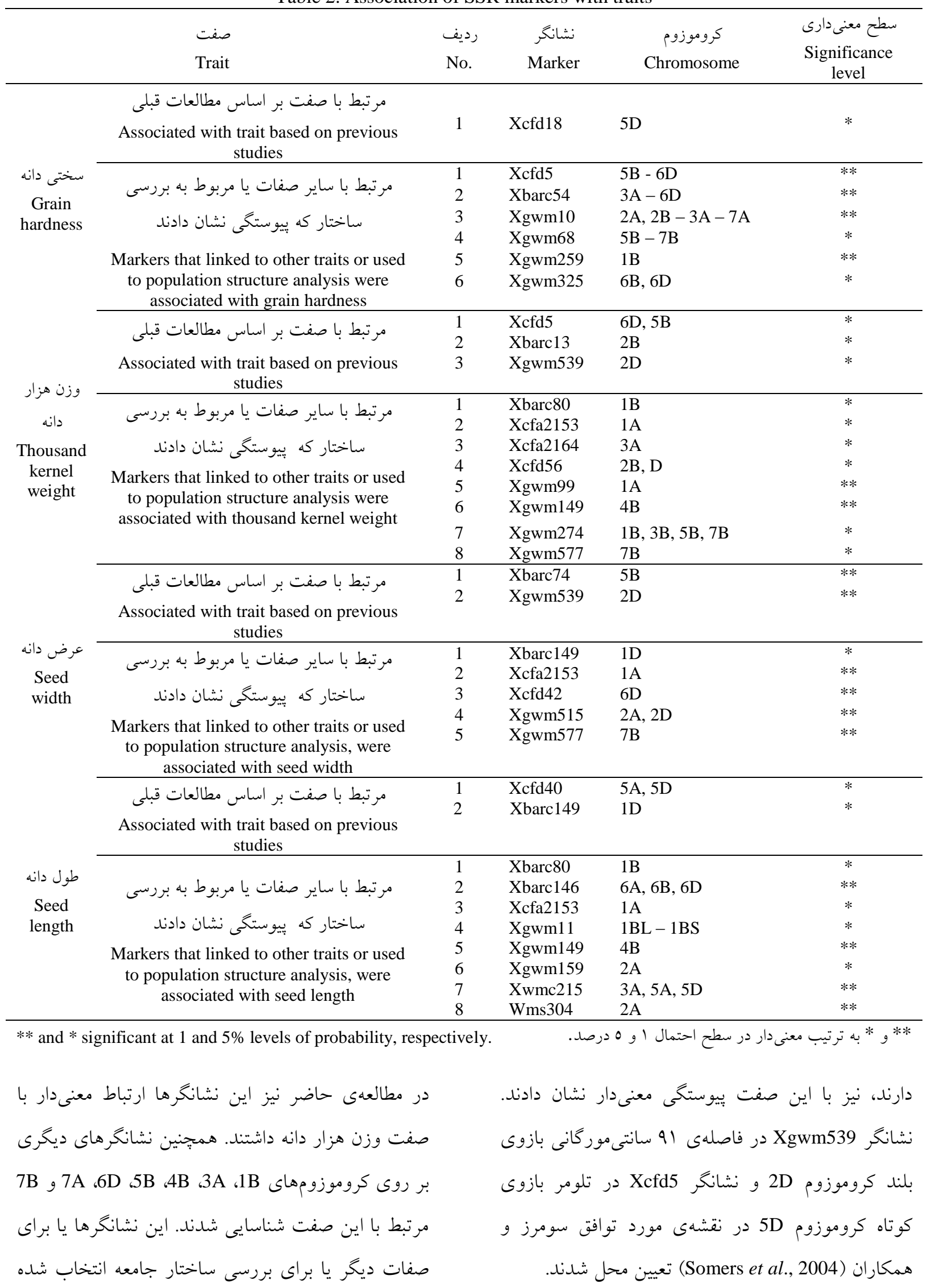


اساس مطالعات قبلى ييوسته با صفت طول دانه معرفى شده بودند (Ramya et al., 2010)، مورد استفاده قرار كرفت. تنها دو نشانگر Xcfd40 كه روى كروموزومهاى

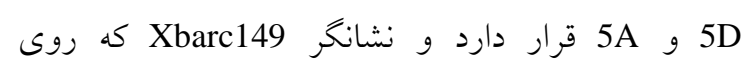
كروموزوم 1D قرار دارد، با اين صفت بيوستخى معنىدار نشان دادند. (جدول Y Y). همجينين نشانخرهاى Xbarc80

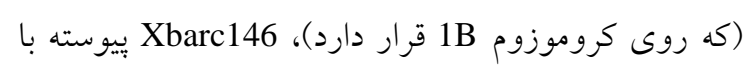
صفت وزن هزار دانه (كه روى كروموزومهاى 6A، 6B،

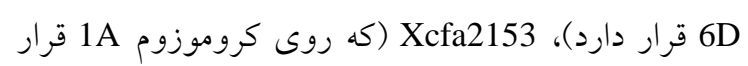
3A, 5A-5D دارد)، Xwmc215 (كه روى كروموزومهاى

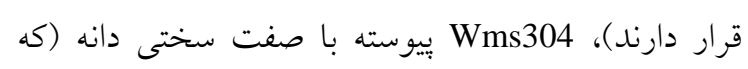

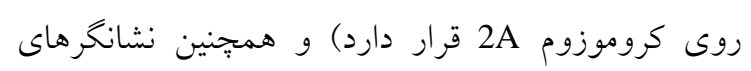
Xgwm149 Xgwm11

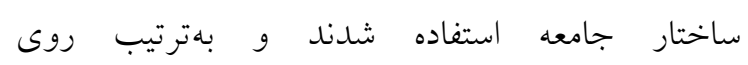

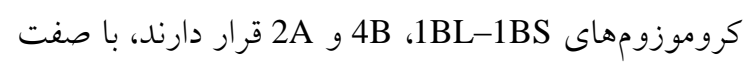
فوق ارتباط معنىدار نشان دادند. با توجه به اينكه نشانخرهايى كه روى كروموزومهاى 2A و 1B قرار دارند بيش از يكبار با صفت طول دانه بيوستخى نشان دادند،

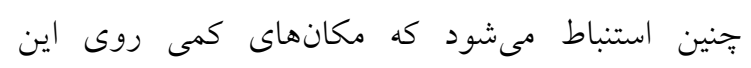
كروموزومها نيز در كتترل اين صفت نقش داشته باشند. دو نشانخر Xcfd40 و Xbarc149 در اين مطالعه ارتباط معنى دار با صفت طول دانه داثتند كه در نقشهى مورد توافق سومرز و همكاران (Somers et al., 2004)، به به مدول ترتيب در فاصلهى rV سانتى موركانى بازوى كوتاه كروموزوم 5D و فاصلهى ع السانتىموركانى بازوى كوتاه

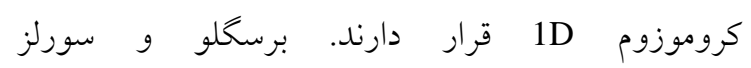

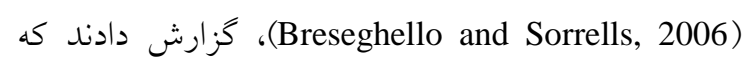
نشانگر Xgwm539 در كروموزوم 2D، ارتباط معنىدار با طول دانه دارد. علاوه بر اين، نشانكرهاى Xbarc308 و 5A كه به ترتيب در كروموزومهاى SBmc150 قرار دارند با صفت طول دانه ييوستخى بسيار معنى دار
بودند. علاوه بر نشانخرهايى كه در مطالعات قبلى با اين صفت بيوستكى داشتند (كه مطالعه حاضر نيز برخى از

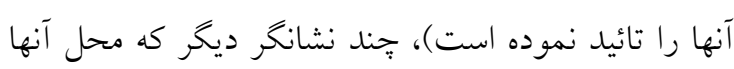
در كروموزومهاى 7B، 1B و 1A، قرار دارد و بيش از

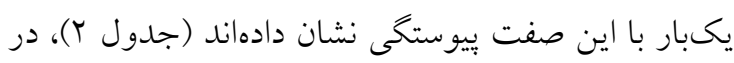
كنترل صفت فوق نقش دارند.

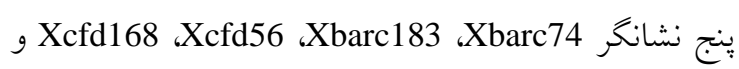
كه قبلاً بهعنوان مكانهاى كمى كنترل كنندهى Xgwm539 صفت عرض دانه معرفى شده بودند، مورد استفاده قرار كرفت (Ramya et al., 2010). با توجه به همبستخى ارتباطى انجام شده در تحقيق حاضر از اين تعداد، تنها دو نشانگر Xbarc74 و Xgwm539 كه به ترتيب روى كروموزومهاى 5B و 2D قرار دارند، ارتباط معنىدار با اين صفت نشان دادند. همجنين نشانكرهاى Xgwm515، Xgwm577 و Xcfd42 كه به ترتيب روى كروموزومهاى

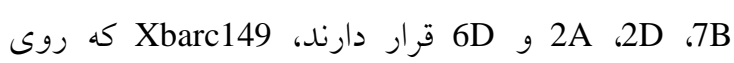
كروموزوم 1D قرار دارد و Xcfa2153 كه روى كروموزوم 1A قرار دارد، با صفت عرض دانه ارتباط معنىدار نشان دادند. نشانكر Xgwm539 در كنترل دو صفت وزن هزار دانه و عرض دانه و نشانكر Xbarc149 در كتترل طول و

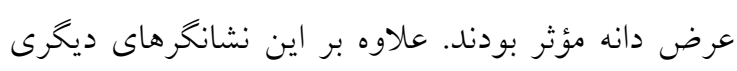
كه مرتبط با ساير صفات و يا براى بررسى ساختار جامعه انتخاب شده بودند و در كروموزومهاى 7B، 6D، 2D، و 1A قرار داشتند با اين صفت بيوستگى نشان دادند.

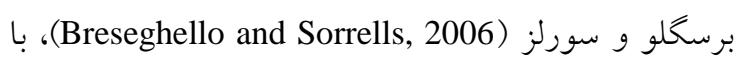
استفاده از نقشهيابى ارتباطى در ارقام گندم نان بيوستخى

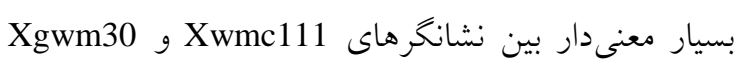
كه در كروموزوم 2D قرار دارند، با صفت عرض و وزن عين دانه را خزارش كردند.

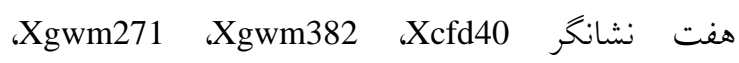
Xbarc149،Xwmc317 
يا براى بررسى ساختار جامعه استفاده شدهاند، ولى در

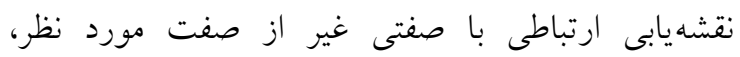
بيوستكى نشان دادهاند، كه ممكن است حاصل اشتباه نوع بوده و اين وييوستى دروغين باشد. علاوه براين، I

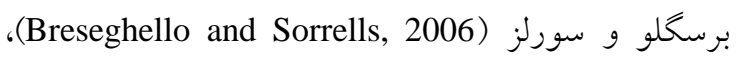
اظهار داشتند كه در نقشهيابى ارتباطى در مقايسه با نقشهيابى كيو.تى.ال، احتمال وقوع اشتباه نوع I و II وجود دارد. اشتباه نوع I زمانى رخخ مىدهد كه ساختار جمعيت در نظر كرفته نشود (Pritchard et al., 2000). وقوع اشتباه نوع II و كاهش قدرت نقشهيابى ارتباطى مىتواند

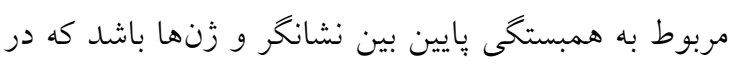
نتيجه ميزان عدم تعادل كامتى كم اين امر رخ مىدهد. همجنين ممكن است در نتيجه فراوانى متفاوت آللها باشد. صفات كمى بلهوسيله تعدادى زن كتترل شده و كنترل زرنتيكى اين صفات بهطور طبيعى تغييرات آللى زيادى در جند زن دارد و تحت تأثير محيط نيز قرار مى كيرند. صفات كيفى دانه كندم هم كه بهعنوان صفات كمى شناخته شدهاند، بهوسيله كروهى از زنها كنترل مىشوند كه بهشدت تحت تأثير تغييرات محيطى قرار دارند. بنابراين ممكن است نتايج متفاوت بهدست بيايد. ييشنهاد مىشود براى تعيين بهتر ساختار جمعيت مورد بررسى، از تعداد بيشترى نشانگر استفاده شده و با تكرار

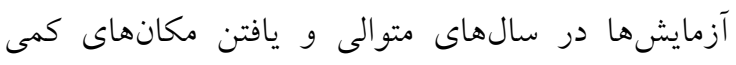
ثابت كنترل كننده صفات، نتايج قابل استناد بهدست آورد و از آنها در اصلاح گندم استفاده نمود.
داشتند. برخى نشانگرها بهطور همزمان بيوستخى معنىدار با دو صفت داشتند؛ مانند نشانكرهاى Xcfd5 (سختى دانه و وزن هزار دانه)، Xgwm539 (عرض دانه و وزن هزار دانه) و Xgwm577 (وزن هزار دانه و عرض دانه). بهنظر مىرسد مكانهاى زنى اين نشانخرها مربوط به زنهاى

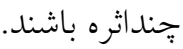

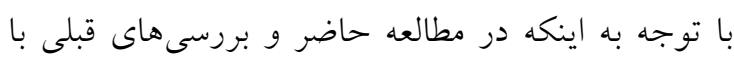

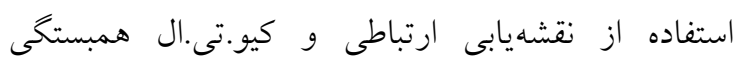
معنى دار بين نشانگرهاى موجود روى كروموزوم 2D و صفات طول، عرض و وزن دانه وجود داشت، بنابراين

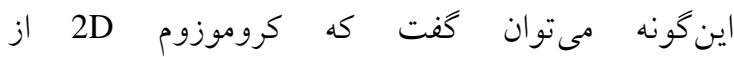
كروموزومهايى است كه نقش مهمى در كتترل صفات فوق دارد. در مطالعه ديخرى كه در ارقام دانه نرم گندم نان با استفاده از نقشهيابى ارتباطى انجام شد، براى وزن هزار

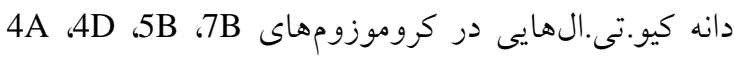
و 2D شناسايى شد (Jochen et al., 2011). همانطور كه ملاحظه مىشود كيو.تى.الهاى كنترل كننده سه صفت فوق بر روى كروموزومهاى مختلف كندم بر اكنده شدهاند.

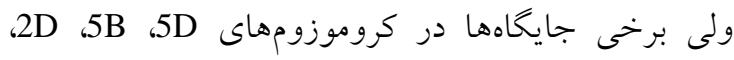

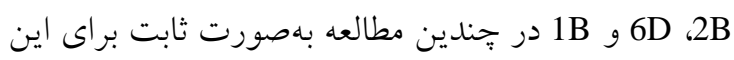
صفات بهعنوان مكانهاى كنترل كننده معرفى شدهاند كه نتايج مطالعه حاضر نيز آنها را تأييد مىنمايد. بنابراين

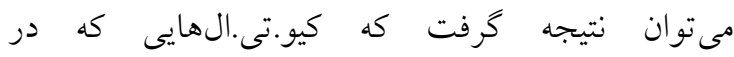
كروموزومهاى زنوم B و D قرار دارند، نقش مهمى در كتترل طول، عرض و وزن دانهى گندم دارند. همانطـور كه در نـتايج مــلاحظــهـ شــد، برخسى

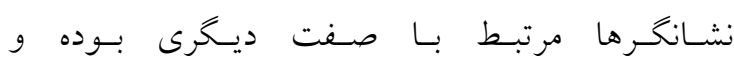

\section{References}

Ammiraju, J.S.S., Dholakia, B.B., Santra, D.K., Singh, H., Lagu, M.D., Tamhankar, S.A., Dhaliwal, H.S., Rao, V.S., Gupta,V.S. and Ranjekar, P.K. (2001). Identification of Inter Simple Sequence Repeat (ISSR) markers associated with seed size in wheat. Theoretical and Applied Genetics, 102: 726-732. 


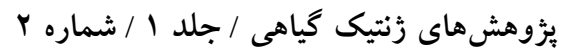

Arbelbide, M. and Bernardo, R. (2006). Mixed-model QTL mapping for kernel hardness and dough strength in bread wheat. Theoretical and Applied Genetics, 112: 885-890.

Breseghello, F. and Sorrells, M.E. (2006). Association mapping of kernel size and milling quality in wheat (Triticum aestivum L.) cultivars. Genetics, 172: 1165-1177.

Breseghello, F. and Sorrells, M.E. (2007). QTL analysis of kernel size and shape in two hexaploid wheat mapping populations. Field Crops Research, 101: 172-179.

Campbell, K.G., Bergman, C.J., Gualberto, D.G., Anderson, J.A., Giroux, M.J., Hareland, G., Fulcher, R.G., Sorrells, M.E. and Finney, P. L. (1999). Quantitative trait loci associated with kernel traits in a soft xhard wheat cross. Crop Science, 39: 1184-1195.

Cardon, L.R. and Bell, J.I. (2001). Association study designs for complex diseases. Nature Reviews Genetics, 2: 91-99.

Committee, A.A.o.C.C.A.M. (2000). Approved Methods of the American Association of Cereal Chemists, $10^{\text {th }}$ edn, AACC, University of Michigan, USA.

Crepieux, S., Lebreton, C., Flament, P. and Charmet, G. (2005). Application of a new IBD-based QTL mapping method to common wheat breeding population: analysis of kernel hardness and dough strength. Theoretical and Applied Genetics, 111: 1409-1419.

Dholakia, B.B., Ammiraju, J.S.S., Santra, D.K., Singh, H., Katti, M.V., Lagu, M.D., Tmhankar, S.A., Rao., V.S., Gupta, V.S., Dhaliwal, H.S. and Ranjekar, P.K. (2001). Molecular marker analysis of protein content using PCR-Based markers in wheat. Biochemical Genetics, 39: 325-338.

Dholakia, B.B., Ammiraju, J.S.S., Singh, H., Lagu, M.D., Röder, M.S. and Rao, V.S, Dhaliwal, H.S., Ranjekar, P.K., Gupta1, V.S., and Weber, W.E. (2003). Molecular marker analysis of kernel size and shape in bread wheat. Plant Breeding, 122: 392-395.

Doyle, J.J. and Doyle. J.L. (1987). A rapid DNA isolation procedure for small quantities of fresh leaf tissue. Phytochemistry Bulletin, 19:11-15.

Galande, A.A., Tiwari, R., Ammiraju, J.S.S., Santra, D.K., Lagu, M.D., Rao, V.S., Gupta, V.S., Misra, B.K., Nagarajan, S. and Ranjekar, P.K. (2001). Genetic analysis of kernel hardness in bread wheat using PCR based markers. Theoretical and Applied Genetics, 103: 601-606.

Giroux, M.J. and Morris, C.F. (1997). A glycine to serine change in puroindoline $b$ is associated with wheat grain hardness and low levels of starch-surface friabilin. Theoretical and Applied Genetics, 95: 857-864.

Giura, A. and Saulescu, N.N. (1996). Chromosomal location of genes controlling grain size in a large grained selection of wheat (Triticum aestivum L.). Euphytica, 89: 77-80.

Igrejas, G., Leroy, P., Charmet, G., Gaborit, T., Marionm, D. and Branlard, G. (2002). Mapping QTLs for grain hardness and puroindoline content in wheat (Triticum aestivum L.). Theoretical and Applied Genetics, 106: 19-27.

Jannink, J.L., Bink, M.C. and Jansen, R.C. (2001). Using complex plant pedigrees to map valuable genes. Trends in Plant Science, 6: 337-342.

Kumar, N., Kulwal, P., Gaur, A., Tyagi, A., Khurana, J., Khurana, P., Balyan, H. and Gupta, P. (2006). QTL analysis for grain weight in common wheat. Euphytica, 151: 135-144.

Kunert, A., Naz, A.A. and Dedeck, O. (2007). AB-QTL analysis in winter wheat: I. Synthetic hexaploid wheat (T. turgidum ssp. dicoccoides $\times T$. tauschii) as a source of favourable alleles for milling and baking quality traits. Theoretical and Applied Genetics, 115: 683-695. 
Lie, Y., Zhou, R., Wang, J., Liao, X., Branlard, G. and Jia, J. (2012). Novel and favorable QTL allele clusters for end-use quality revealed by introgression lines derived from synthetic wheat. Molecular Breeding, 29: 627-643.

Marshall, D.R., Mares, D.J., Moss, H.J. and Ellison, F.W. (1986). Effects of grain shape and size on milling yields in wheat. Experimental studies. Australian Journal of Agricultural Research, 37: 331-342.

Mattern, P.J., Morris, R., Schmidt, J.W. and Johnson, V.A. (1973). Locations of genes for kernel properties in the wheat variety 'Cheyenne' using chromosome substitution lines. In: Agricultural Experimental Station (Sears, E.R, and Sears, L.M.S., Eds) pp. 703-707, Proc $4^{\text {th }}$ international wheat genetics symposium, University of Missouri, Columbia.

Narasimhamoorthy, B., Gill, B.S., Fritz, A.K., Nelson, J.C. and Brown-Guedira, G.L. (2006). Advanced backcross QTL analysis of a hard winter wheat $\times$ synthetic wheat population. Theoretical and Applied Genetics, 112: 787-796.

Oraguzie, N.C. and Wilcox. P.L. (2007). An overview of association mapping. In: Association mapping in plants (Oraguzie, N., Rikkerink, E.A., Gardiner, S. and De Silva, H.N., Eds) pp. 1-9, Springer, New York, USA.

Perretant, M.R., Cadalen, T., Charmet, G., Sourdille, P., Nicolas, P., Boeuf, C., Tixier, M.H., Branlard, G., Bernard, S. and Bernard, M. (2000). QTL analysis of bread-making quality in wheat using a doubled haploid population. Theoretical and Applied Genetics, 100: 1167-1175.

Pritchard, J.K., Stephens, M., Rosenburg, N.A. and Donnelly, P. (2000). Association mapping in structured populations. American Journal of Human Genetics, 37: 170-181.

Pritchard, J.K. and Wen, X. (2007). Documentation for structure Software, version 2.3. Department of Human Genetics, University of Chicago, Chicago, USA.

Pritchard, J.K., Wen, X. and Flash, D. (2010). Documentation for structure Software, version 2.3. Department of Human Genetics, University of Chicago, Chicago, USA.

Pshenichnikova, T.A., Ermakova, M.F., Chistyakova, A.K., Shchukina, L.V., Berezovskaya, E.V., Lochwasser, U., Röder, M. and Börner, A. (2008). Mapping of the quantitative trait loci (QTL) associated with grain quality characteristics of the bread wheat grown under different environmental conditions. Russian Journal of Genetics, 44: 74-84.

Rafalski, J.A., Morgante, M., Powell, W., Vogel, J. M. and Tingey, S.V. (1996). Generating and using DNA markers in plants. In: Analysis of Non-mammalian Genomes: a practical guide (Birren, B. and Lai, E., Eds) pp. 75-134, Academic Press, Boca Raton, Florida, USA.

Ramya, P., Chaubal, A., Kulkarni, K, Gipta, L., Kadoo, N., Dhaliwal, H.S., Chhuneja, P., Lagu, M. and Gupta, V. (2010). QTL mapping of 1000-kernel weight, kernel length, and kernel width in bread wheat (Triticum aestivum L.). Journal of Applied Genetics, 51: 421-429.

Roder, M.S., Korsun, V., Wendehake, K., Plaschke, J., Tixier, M.H., Leroy, P. and Ganal, M.W. (1998). A microsatellite map of wheat. Genetics, 149: 2007-2023.

Somers, D.J., Fedak, G, and Savard, M. (2003). Molecular mapping of novel genes controlling Fusarium head blight resistance and deoxynivalenol accumulation in spring wheat. Genome, 46: 555-564.

Somers, D.J., Isaac, P, and Edwards, K. (2004). A high density microsatellite consensus map of bread wheat (Triticum aestivum L.). Theoretical and Applied Genetics, 109: 1105-1114. 


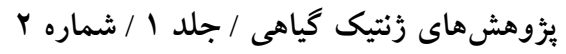

Sourdille, P., Perretant, M.R., Charmet, G., Leroy, P., Gautier, M.F., Joudrier, P., Nelson, J.C., Sorrells, M.E. and Bernard, M. (1996). Linkage between RFLP markers and genes affecting kernel hardness in wheat. Theoretical and Applied Genetics, 93: 580-586.

Toi, J.T., Hareland, G.A., Simsek, S., Chao, S. and Anderson, J.A. (2010). Genome mapping of kernel characteristics in hard red spring wheat breeding lines. Theoretical and Applied Genetics, 121: 717-730.

Varshney, R.K., Prasad, M., Roy, J.K., Kumar, N., Harjit, S., Dhaliwal, H.S., Balyan, H.S. and Gupta, P.K. (2000). Identification of eight chromosomes and a microsatellite marker on 1AS associated with QTLs for grain weight in bread wheat. Theoretical and Applied Genetics, 100: 1290-1294.

Wiersma, J.J., Busch, H., Fulcher, G.G. and Hareland, G. (2001). Recurrent selection for kernel weight in spring wheat. Crop Science, 41: 999-1005.

Zhang, Y., Tang, J. and Zhang, Y. (2011). QTL mapping for quantities of protein fractions in bread wheat (Triticum aestivum L.). Theoretical and Applied Genetics, 122: 971-987.

Zhu, C., Gore, M.E., Buckler, S. and Yu, J. (2008). Status and prospects of association mapping in plants. The plant genome, 1: 5-20. 


\title{
Detection of QTLs Associated to Some Grain Traits in Bread Wheat (Triticum aestivum L.), Using Association Mapping
}

\section{Reza Mir Drikvand ${ }^{1, *}$, Goodarz Najafian', Mohammad Reza Bihamta ${ }^{3}$ and Asa Ebrahimi ${ }^{4}$}

1- Assistant Professor, Department of Agronomy and Plant Breeding, Khorramabad Branch, Islamic Azad University, Khorramabad, Iran

2- Associate Professor, Cereal Chemistry and Technology Unit, Seed and Plant Improvement Institute, Karaj, Iran

3- Professor, Department of Agronomy and Plant Breeding, University of Tehran, Tehran, Iran

4- Assistant Professor, Department of Plant Biotechnology, Science and Research Branch, Islamic Azad University, Tehran, Iran

(Received: June 10, 2014- September 10, 2014)

\begin{abstract}
This study was conducted to identify markers associated with some kernel traits in bread wheat in two separate experiments under field and laboratory. One hundred wheat genotypes were evaluated in an alpha lattice experimental design with two replications. Grain hardness, seed length, seed width and thousand kernel weights were measured. Association mapping was performed based on 96 unlinked and 22 SSR QTL linked markers, using structure and Tassel software. Correction for population structure was performed using genome wide SSR markers so that genotypes were divided into six subpopulations. Totally, 35 SSR markers linked to traits were detected; eight of them being QTL linked markers and other markers that were linked to traits, were used to investigate population structure. The QTLs linked markers were as follows: Chromosomes 5B, 5D and 6D had three QTL for grain hardness. Nine QTLs were detected on chromosomes 1A, 1B, 2A, 2B, 2D, 5B, 5D, 6D and 7B for kernel length, kernel width and thousand kernel weights. The results of this study demonstrate that association mapping is a useful approach to complement and enhance previous QTL information for marker-assisted selection in wheat.
\end{abstract}

Keywords: Kernel traits, Wheat, Association mapping, QTL

\footnotetext{
*Corresponding Author, E-mail: mirderikvand@ khoiau.ac.ir
} 